\title{
A 350-S Recovery Period Does Not Necessarily Allow Complete Recovery of Peak Power Output during Repeated Cycling Sprints
}

\author{
Ryouta Matsuura, Hisayoshi Ogata, Takahiro Yunoki, Takuma Arimitsu, \\ Takehide Kimura, and Tokuo Yano \\ Laboratory of Exercise Physiology, Graduate School of Education, Hokkaido University
}

\begin{abstract}
The aim of this study was to determine whether a 350 -s recovery period allows recovery of peak power output (PPO) to its initial value under the condition of a blood lactate (La) concentration higher than $10 \mathrm{mmol} \cdot \mathrm{L}^{-1}$ during repeated cycling sprints (RCS). RCS (10×10-s cycling sprints) were performed under two conditions. Under one condition, the recovery period of RCS was fixed at $35 \mathrm{~s}\left(\mathrm{RCS}_{35}\right)$, and under the other condition, a 350-s recovery period was set before the 5th and 9th sets, and a 35-s recovery period was set before the other sets $\left(\mathrm{RCS}_{\text {comb }}\right)$. In $\mathrm{RCS}_{\text {comb }}$, PPO in the 5th set recovered to that in the 1st set, but PPO in the 9th set did not. Under both conditions, blood La concentration progressively increased and reached approximately $14 \mathrm{mmol} \cdot \mathrm{L}^{-1}$ at the end of the RCS. In $\mathrm{RCS}_{\text {comb }}, \dot{\mathrm{V}} \mathrm{O}_{2}$ immediately before the 5 th set was not significantly different from that immediately before the 9 th set. Mean power frequency (MPF) values estimated by a surface electromyogram from the vastus lateralis in the 5th and 9th sets were significantly higher in $\mathrm{RCS}_{\text {comb }}$ than in $\mathrm{RCS}_{35}$. In conclusion, a 350-s recovery period does not allow recovery of PPO to its initial value under the condition of a blood La concentration of $14 \mathrm{mmol} \cdot \mathrm{L}^{-1}$ during RCS. $J$ Physiol Anthropol 26(2): 51-57, $2007 \mathrm{http} / / /$ www.jstage.jst.go.jp/ browse/jpa2
\end{abstract}

[DOI: 10.2114/jpa2.26.51]

Keywords: blood lactate concentration, oxygen uptake, muscle fatigue, surface electromyogram

\section{Introduction}

Despite the fact that many sporting events are characterized by maximal intermittent sprint exercise in which a short-term sprint is repeated with passive recovery and/or low-intensity exercise, the determinant of performance during maximal intermittent sprint exercise is still not clear. Traditionally, sports scientists have argued that depleted energy substrate and metabolite accumulation reduce performance in such exercise (Gaitanos et al., 1993).
In a single 6-10-s sprint, ATP production resulting from the breakdown of phosphocreatine (PCr) mainly limits peak power output (PPO) (Nevill et al., 1996). Hirvonen et al. (1987) found in a series of maximal sprints $(40-100 \mathrm{~m})$ that skeletal muscle $\mathrm{PCr}$ store is greatly depleted after $5-7 \mathrm{~s}$, indicating that anaerobic glycolysis must provide the majority of ATP to complete the sprint. Therefore, when short-term sprints are repeated before $\mathrm{PCr}$ resynthesis is complete, the energy supply derived from anaerobic glycolysis becomes important for PPO (Dawson et al., 1997), resulting in lactate accumulation (Gaitanos et al., 1993). It is well known that the accumulated lactate increases hydrogen ions $\left(\mathrm{H}^{+}\right)$, resulting in reduction of muscle $\mathrm{pH}$. The reduced muscle $\mathrm{pH}$ causes muscle fatigue (Fitts, 1994). Thus, when short-term sprints are repeated before $\mathrm{PCr}$ resynthesis is complete, both incomplete repletion of the $\mathrm{PCr}$ store and subsequent metabolic acidosis reduce PPO (Gaitanos et al., 1993).

However, Sahlin and Ren (1989) have shown that, regardless of the reduced muscle $\mathrm{pH}$, maximal voluntary contraction (MVC) was duplicated when the $\mathrm{PCr}$ value had recovered to the resting level. A 3-min recovery period allowed PCr to recover to $90 \%$ and $84 \%$ of resting values after a single 6 -s sprint and repeated sprints $(5 \times 6$-s sprints $)$ with 24 -s recovery periods, respectively (Dawson et al., 1997). In addition, previous studies have shown that the PCr store utilized by high-intensity exercise recovered to almost the resting level in 6 min (Arsac et al., 2004; Harris et al., 1976; McCann et al., 1995). We therefore hypothesize that even if both incomplete recovery of $\mathrm{PCr}$ resynthesis and subsequent reduced muscle $\mathrm{pH}$ reduce PPO during repeated sprints with short-term recovery periods, a subsequent 6-min recovery period, in which $\mathrm{PCr}$ is fully resynthesized, will allow recovery of PPO to its initial value regardless of the reduced muscle $\mathrm{pH}$.

Matsuura et al. (2006) have shown that PPO remained unchanged during repeated cycling sprints $(\mathrm{RCS})(10 \times 10$-s sprints) with 350-s recovery periods. They found that blood lactate (La) concentration reached approximately $10 \mathrm{mmol} \cdot \mathrm{L}^{-1}$ at the end of RCS with 350 -s recovery periods. Previous studies have shown that a blood La concentration of 
$10 \mathrm{mmol} \cdot \mathrm{L}^{-1}$ did not reduce PPO during $\mathrm{RCS}$ with long (2-5 $\mathrm{min}$ ) recovery periods (Balsom et al., 1992; Ratel et al., 2002). The results of these studies seemingly support the idea that a relatively longer $(2-6 \mathrm{~min})$ recovery period allows recovery of PPO to its initial value regardless of the reduced muscle $\mathrm{pH}$. However, no studies have shown whether a long recovery period allows recovery of PPO to its initial value under the condition of a blood La concentration higher than $10 \mathrm{mmol} \cdot \mathrm{L}^{-1}$.

In the RCS $(10 \times 10$-s sprints $)$ with 35 -s recovery periods in the study by Matsuura et al. (2006), the blood La concentration at the end of RCS (approximately $14 \mathrm{mmol} \cdot \mathrm{L}^{-1}$ ) was higher than that in the RCS with 350-s recovery periods. Therefore, if 35 -s recovery periods in RCS with 35-s recovery periods are periodically replaced with 350 -s recovery periods, it would be possible to determine whether a 350-s recovery period, in which $\mathrm{PCr}$ seems to be completely resynthesized, allows recovery of PPO to its initial value under the condition of a blood La concentration higher than $10 \mathrm{mmol} \cdot \mathrm{L}^{-1}$.

The aim of this study was to determine whether a 350-s recovery period allows recovery of PPO to its initial value under the condition of a blood La concentration higher than $10 \mathrm{mmol} \cdot \mathrm{L}^{-1}$ during $\mathrm{RCS}$.

\section{Methods}

\section{Subjects}

Eight healthy male undergraduate students participated in this study. The subjects' mean age, height, and body mass were $20.4 \pm 1.4$ (SD) yr, $171.2 \pm 5.9 \mathrm{~cm}$, and $66.7 \pm 10.6 \mathrm{~kg}$, respectively. They had no neuromuscular disorders and were competitive, trained swimmers. Their weekly training distance averaged approximately $20000 \mathrm{~m}$. Each subject signed a statement of informed consent following a full explanation regarding the nature of the experiment. The Ethics Committee of Hokkaido University Graduate School of Education approved the present study.

\section{Design}

Each subject attended our laboratory for three tests. The time interval between two consecutive tests was at least 3 days, and all tests were completed within 2 weeks. On the first test day, the subjects' body characteristics were measured, and each subject performed half of the RCS with the 35-s recovery periods described below to become familiar with RCS. Body mass (BM) was used to determine the loads of the cycling sprint. Each subject was instructed to refrain from intense physical exercise, drinking alcohol, and taking caffeine for $24 \mathrm{~h}$ prior to each visit. None of the subjects had a smoking habit.

\section{Experimental protocol}

Each subject came to the laboratory $30 \mathrm{~min}$ before the start of the test. Experimental instruments were then fitted to each subject. After resting for $3 \mathrm{~min}$ on the bicycle seat, each subject performed two RCS tests in randomized order on separate days. One test consisted of ten 10-s cycling sprints with 35-s recovery periods (340s of low-intensity cycling exercise with $0 \mathrm{~W}$ at $60 \mathrm{rpm}$ and 10 -s passive recovery on the bicycle seat: $\left.\mathrm{RCS}_{35}\right)$. The other test $\left(\mathrm{RCS}_{\mathrm{comb}}\right)$ consisted of ten 10 -s cycling sprints with eight 35 -s recovery periods $(25 \mathrm{~s}$ of low-intensity cycling exercise with $0 \mathrm{~W}$ at $60 \mathrm{rpm}$ and $10-\mathrm{s}$ passive recovery on the bicycle seat) immediately before the 2nd, 3rd, 4th, 6th, 7th, 8th, and 10th sets, respectively, and two 350 -s recovery periods (340-s low-intensity cycling exercise with $0 \mathrm{~W}$ at $60 \mathrm{rpm}$ active recovery and 10 -s passive recovery) immediately before the 5th and 9th sets, respectively. All cycling sprints were performed with a load (F) [N] of $0.075 \cdot \mathrm{BM} \cdot 9.81^{-1}$ (Ayalon et al., 1974) from a stationary start. Subjects were instructed to pedal as many revolutions as possible during the cycling sprints. The number of sets in the RCS was not announced in advance, to prevent the subjects from making an unconscious plan for whole power output.

\section{Peak power output during 10-s cycling sprints}

All exercise tests were carried out on a bicycle ergometer (POWERMAX-V $\mathrm{V}_{\mathrm{II}}$, Combi, Tokyo, Japan). The duration and load were adjusted by a built-in computer. The computer also calculated mean power output and peak rpm $\left(\operatorname{Rpm}_{\text {peak }}\right)$ in a given exercise, and displayed the results. Since the screen on the bicycle ergometer displayed $\mathrm{Rpm}_{\text {peak }}$, the screen was covered. Each subject's feet were strapped to the pedals to prevent them from slipping. The seat height was adjusted so that there was a slight bend in the knee joint when the foot pedal was at its lowest position. PPO was calculated by the following equation:

$$
\text { PPO }[\mathrm{W}]=\mathrm{Rpm}_{\text {peak }} \cdot 6 \cdot \mathrm{F} \cdot 0.624^{-1} \text {, }
$$

where 6 is the distance calculated by the built-in computer as the flywheel went into a 360-degree roll [m], and 0.624 is the value for transforming $\mathrm{Nm}$ units to $\mathrm{W}$ units $\left[\mathrm{Nm} \cdot \mathrm{min}^{-1} \cdot \mathrm{W}^{-1}\right]$. To reduce variation due to differences in the body characteristics of subjects, $\mathrm{PPO}$ divided by $\mathrm{BM}\left(\mathrm{PPO} \cdot \mathrm{BM}^{-1}\right)$ was used.

\section{Blood lactate concentration}

Blood samples $(25 \mu \mathrm{L})$ were collected from fingertips using capillary tubes, and analyzed using a lactate analyzer (YSI1500 sport, YSI, Tokyo, Japan) to measure blood La concentration. The lactate analyzer was calibrated by a standard lactate solution of $5 \mathrm{mmol} \cdot \mathrm{L}^{-1}$ before each test. Blood was sampled at rest and immediately after the 5th and 10th cycling sprints.

\section{Oxygen uptake}

Data on oxygen uptake ( $\dot{\mathrm{V} O} 2)$ were obtained breath by breath using a respiratory gas analyzer (AE-280S, Minato Medical Science, Osaka, Japan). Ventilation ( $\dot{\mathrm{VE}}$ ) was measured by a hot-wire flow meter, which was calibrated with 
a syringe of known volume $(2.0 \mathrm{~L}) \cdot \mathrm{O}_{2}$ and $\mathrm{CO}_{2}$ concentrations were measured by a zirconium sensor and infrared absorption analyzer, respectively. The gas analyzer was calibrated by known standard gas $\left(\mathrm{O}_{2}: 15.17 \%, \mathrm{CO}_{2}: 4.92 \%\right)$. $\dot{\mathrm{VO}}_{2}$ was measured continuously during rest, exercise, and recovery periods. For each 15-s interval, the averages of $\dot{\mathrm{VO}}_{2}$ were calculated. To reduce variation due to difference in the body characteristics of subjects, $\dot{\mathrm{V}} \mathrm{O}_{2}$ divided by $\mathrm{BM}\left(\dot{\mathrm{VO}}_{2} \cdot \mathrm{BM}^{-1}\right)$ was used.

\section{Surface electromyogram}

A surface electromyogram (SEMG) was recorded from the left vastus lateralis (VL) and the left rectus femoris (RF) at a rate of $1000 \mathrm{~Hz}$ during each of the ten cycling sprints. Before attachment of the surface electrodes, the skin was shaved, abraded, and cleaned with alcohol in order to reduce source impedance. A bipolar SEMG sensor (SX230, Biometrics Ltd, United Kingdom; inter-electrode distance of $20 \mathrm{~mm}$ ) was placed on the lateral side of the crural area five fingers proximal from the patella of the belly of the VL and on the lower limb midway between the superior surface of the patella and the anterior superior iliac spine of the belly of the RF. The ground electrode was placed over the right lateral malleolus. The SEMG signals were amplified using an amplifier imbedded in the EMG sensor (bandwidth $=20-450 \mathrm{~Hz}$; common mode rejection ratio, $\mathrm{CMRR}>96 \mathrm{~dB}$; input impedance $>10 \mathrm{~T} \Omega$; gain $=1000)$ and converted into digital signals using an analog-digital converter (MacLab/8s, AD Instruments, Australia). Then SEMG data were processed offline by using analysis software (Acknowledge, BIOPAC Systems, United States). Raw data were filtered using a band pass Finite Impulse Response filter with a cut-off frequency of 10 to $500 \mathrm{~Hz}$. Since a previous study in our laboratory (Matsuura et al. 2005) showed that power output during a 10-s cycling sprint reached a peak at $6.2 \mathrm{~s}$ on average, four seconds (4-8 s) of raw data were used for subsequent analysis. The four seconds of raw data were full-wave-rectified and then integrated (IEMG). Furthermore, the raw data were processed with fast Fourier transform to obtain a frequency power spectrum. The frequency spectrum analysis was restricted to frequencies in the range 5-500 Hz (Kay et al., 2001; St Clair Gibson et al., 2001). Mean power frequency (MPF) was defined as the ratio between spectral moments of orders one and zero (Moritani et al., 1982). IEMG and MPF calculated from raw data of an SEMG in a given time period during dynamic exercise such as a cycling sprint are used to determine neuromuscular activation (Hunter et al. 2003; Kay et al. 2001; St Clair Gibson et al. 2001). The positions of the electrodes for SEMG detection were similar under the two conditions because reference points were marked on the skin. The IEMG and MPF were normalized as a percentage of the 1 st-set value.

\section{Statistical analysis}

Results are presented as means \pm standard deviations (SD).
A paired t-test was used to examine differences between conditions. One-way ANOVA (for $\mathrm{PPO} \cdot \mathrm{BM}^{-1}$ and $\dot{\mathrm{VO}}_{2} \cdot \mathrm{BM}^{-1}$ ) for repeated measures was used to examine the time effect. Two-way ANOVA (for blood La concentration, IEMG, and MPF) for repeated measures on both factors (sprint number and condition) was used. When significant $F$ ratios were found, the means were compared by using TukeyKramer's post-hoc test. If significant interaction was indicated, one-way ANOVA for repeated measures was used to examine the time effect, and a paired t-test was used to examine the difference between conditions. A value of $p<0.05$ was regarded as statistically significant.

\section{Results}

\section{Peak power output during 10-s cycling sprints}

$\mathrm{PPO} \cdot \mathrm{BM}^{-1}$ values in the $1 \mathrm{st}$ set in the two $\mathrm{RCS}$ trials were similar $\left(\mathrm{RCS}_{35}: 10.8 \pm 0.8 \mathrm{~W} \cdot \mathrm{kg}^{-1}, \mathrm{RCS}_{\mathrm{comb}}: 10.7 \pm 0.6\right.$ $\left.\mathrm{W} \cdot \mathrm{kg}^{-1} ; p=0.85\right)$. $\mathrm{PPO} \cdot \mathrm{BM}^{-1}$ values were significantly lower in the 4th-10th sets than in the 1st set in $\mathrm{RCS}_{35}$, and $\mathrm{PPO} \cdot \mathrm{BM}^{-1}$ values were significantly lower in the $3 \mathrm{rd}, 4 \mathrm{th}, 7 \mathrm{th}$, 8th, 9th, and 10th sets than in the 1st set in $\operatorname{RCS}_{\text {comb }}$ (Fig. 1).

\section{Blood lactate concentration}

Blood La concentration recorded immediately after the 5th and 10th cycling sprints are expressed as 5th- and 10th-set values, respectively (Fig. 2). When two-way ANOVA for repeated measures was used, no significant interaction was found in blood $\mathrm{La}$ concentration. No significant effect of the condition on blood $\mathrm{La}$ concentration was found. In both $\mathrm{RCS}_{35}$ and $\mathrm{RCS}_{\text {comb }}$, Blood La concentration was significantly higher in the 5 th and 10th sets than at rest and was significantly higher in the 10th set $\left(\mathrm{RCS}_{35}: 13.9 \pm 3.1 \mathrm{mmol} \cdot \mathrm{L}^{-1}, \mathrm{RCS}_{\mathrm{comb}}: 14.0 \pm 3.1 \mathrm{mmol} \cdot \mathrm{L}^{-1}\right)$ than in the 5 th set $\left(\mathrm{RCS}_{35}: 10.2 \pm 1.4 \mathrm{mmol} \cdot \mathrm{L}^{-1}, \mathrm{RCS}_{\mathrm{comb}}\right.$ : $\left.11.0 \pm 0.9 \mathrm{mmol} \cdot \mathrm{L}^{-1}\right)$.

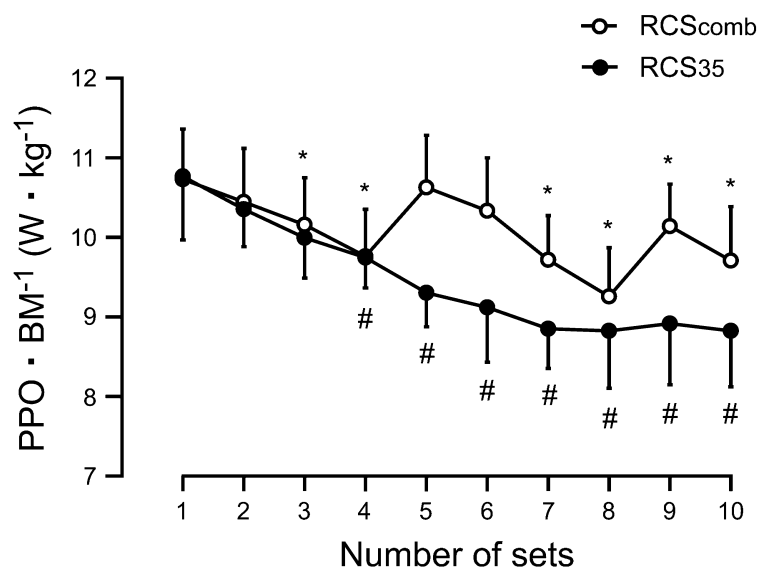

Fig. 1 Changes in peak power output (PPO) divided by body mass (BM) in each of the subjects (PPO $\mathrm{BM}^{-1}$ ) during each of the ten 10-s cycling sprints in $\operatorname{RCS}_{\text {comb }}(\bigcirc)$ and $\operatorname{RCS}_{35}(\mathbf{O})$. *: significantly different $(p<0.05)$ from the value in the 1 st set in $\operatorname{RCS}_{\text {comb }}$ \#: significantly different $(p<0.05)$ from the value in the 1 st set in $\mathrm{RCS}_{35}$. 


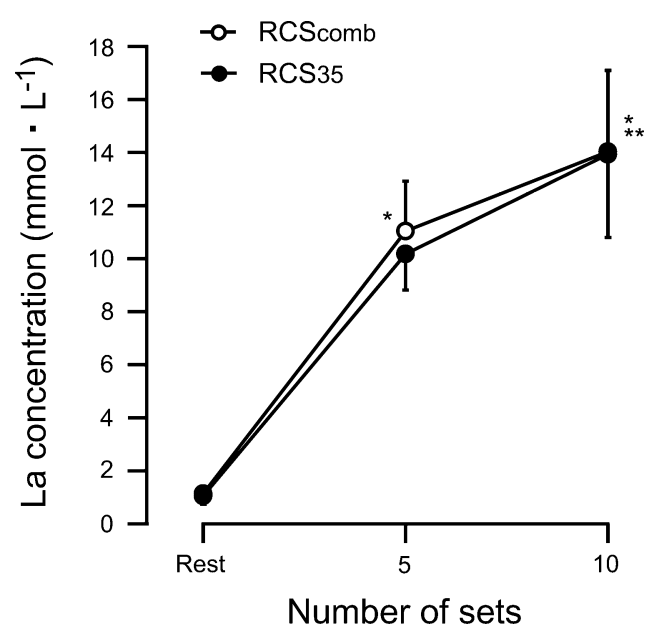

Fig. 2 Changes in blood lactate (La) concentration during $\mathrm{RCS}_{\text {comb }}(\bigcirc)$ and $\operatorname{RCS}_{35}(\bullet)$. *: significantly different $(p<0.05)$ from the value at rest. **: significantly different $(p<0.05)$ from the value in the 5 th set.

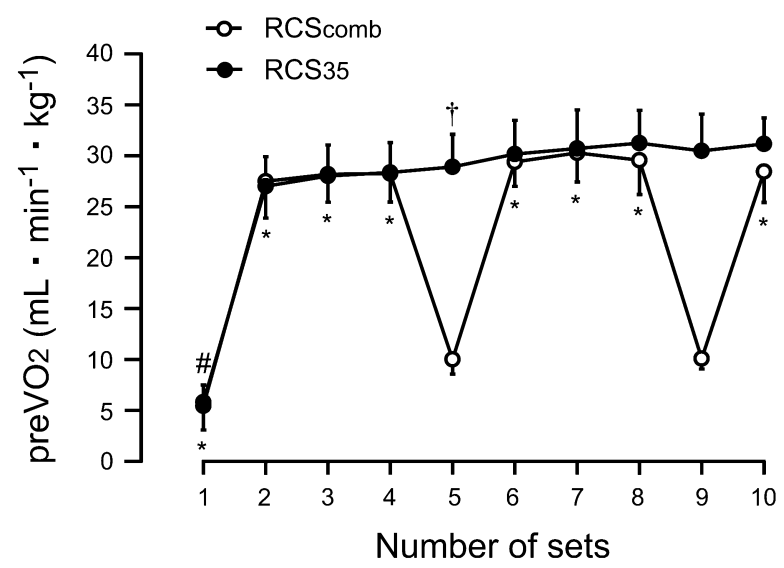

Fig. 3 Changes in $\dot{\mathrm{V}}_{2}$ divided by body mass (BM) in each of the subjects for $15 \mathrm{~s}$ immediately before each of the ten cycling sprints (previ $\dot{\mathrm{V}}_{2}$ ) during $\mathrm{RCS}_{\text {comb }}(\bigcirc)$ and $\operatorname{RCS}_{35}(\bullet)$. *: significantly different $(p<0.05)$ from the value in the 5 th set in $\mathrm{RCS}_{\text {comb. }}$ \#: significantly different $(p<0.05)$ from the value in the 5 th set in $\mathrm{RCS}_{35} . \dagger$ : significant difference $(p<0.05)$ between the value in $\mathrm{RCS}_{\text {comb }}$ and $\mathrm{RCS}_{35}$.

\section{Oxygen uptake immediately before cycling sprints}

The changes in $\dot{\mathrm{VO}}_{2} \cdot \mathrm{BM}^{-1}$ for $15 \mathrm{~s}$ immediately before each of the ten cycling sprints ( $\operatorname{preV} \mathrm{V}_{2}$ ) in the two RCS tests are shown in Fig. 3. The value of $\mathrm{preVO}_{2}$ recorded immediately before the 1st cycling sprint is expressed as the 1st-set value. The 5th-set value was used as a baseline value since active recovery immediately before the 1 st cycling sprint was not performed. In $\mathrm{RCS}_{35}$, preV $\mathrm{O}$ was significantly lower in the 1 st set than in the 5th set, and no significant differences were found from the 2 nd set to the 10th set. In $\mathrm{RCS}_{\text {comb }}, \mathrm{preV}_{2}$ was significantly lower in the 1 st set than in the 5 th set and was significantly higher in the 2nd, 3rd, 4th, 6th, 7th, 8th, and 10th sets than in the 5 th set. There was no significant difference between $\operatorname{preV}_{2}$ value in the 5th set and that in the 9th
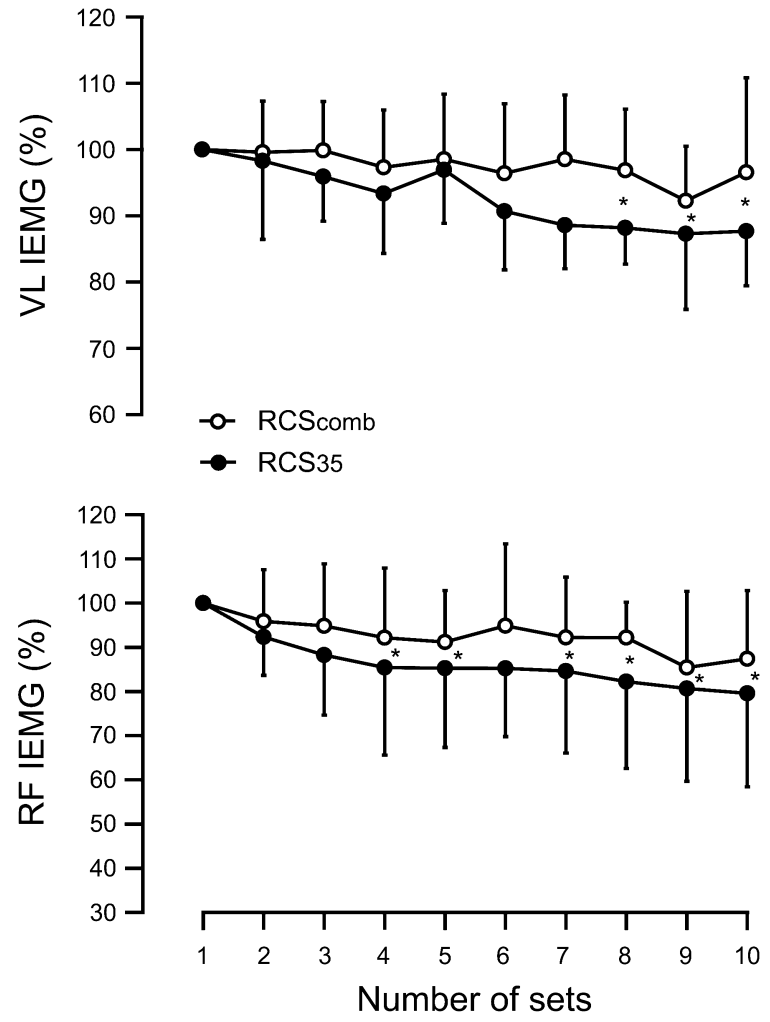

Fig. 4 Changes in integrated EMG (IEMG) from the left vastus lateralis (VL: top) and from the left rectus femoris (RF: bottom) normalized by the 1 st set value during $\operatorname{RCS}_{\text {comb }}(\bigcirc)$ and $\operatorname{RCS}_{35}(\mathbf{O})$.*: significantly different $(p<0.05)$ from the value in the 1 st set.

set. The value of preVंO$_{2}$ in the 5 th set during $\mathrm{RCS}_{35}$ $\left(28.9 \pm 3.2 \mathrm{~mL} \cdot \mathrm{min}^{-1} \cdot \mathrm{kg}^{-1}\right)$ was significantly higher than that in the 5th set during $\mathrm{RCS}_{\text {comb }}\left(10.0 \pm 1.4 \mathrm{~mL} \cdot \mathrm{min}^{-1} \cdot \mathrm{kg}^{-1}\right)$. Because of technical difficulties, the proportion of lowintensity exercise/passive recovery time intervals contributing to $\mathrm{preVO}_{2}$ was not strictly constant.

\section{IEMG and $M P F$}

There were no differences between the two RCS trials in absolute IEMG value (VL: $p=0.43$, RF: $p=0.81$; data not shown) and absolute MPF value (VL: $p=0.57$, RF: $p=0.15$; data not shown) in the 1st set. Changes in IEMG and MPF in the two RCS trials are shown in Fig. 4 and Fig. 5, respectively. When two-way ANOVA for repeated measures was used, no significant interaction was found in IEMG from both the VL and the RF or in MPF from the RF. In both $\mathrm{RCS}_{35}$ and $\mathrm{RCS}_{\text {comb }}$, IEMG from the VL significantly decreased from the 8th set compared to that in the 1st set, and IEMG from the RF was significantly lower in the 4th, 5th, 7th, 8th, 9th, and 10th sets than in the 1st set. MPF from the RF was significantly lower in the 3 rd set than in the 1st set. A significant interaction

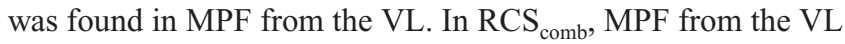
was significantly lower in the 3 rd set than in the 1st set and was significantly higher in the 5 th set than in the 4th set. MPF values from the $\mathrm{VL}$ in the 5 th and 9 th sets during $\mathrm{RCS}_{\text {comb }}$ 


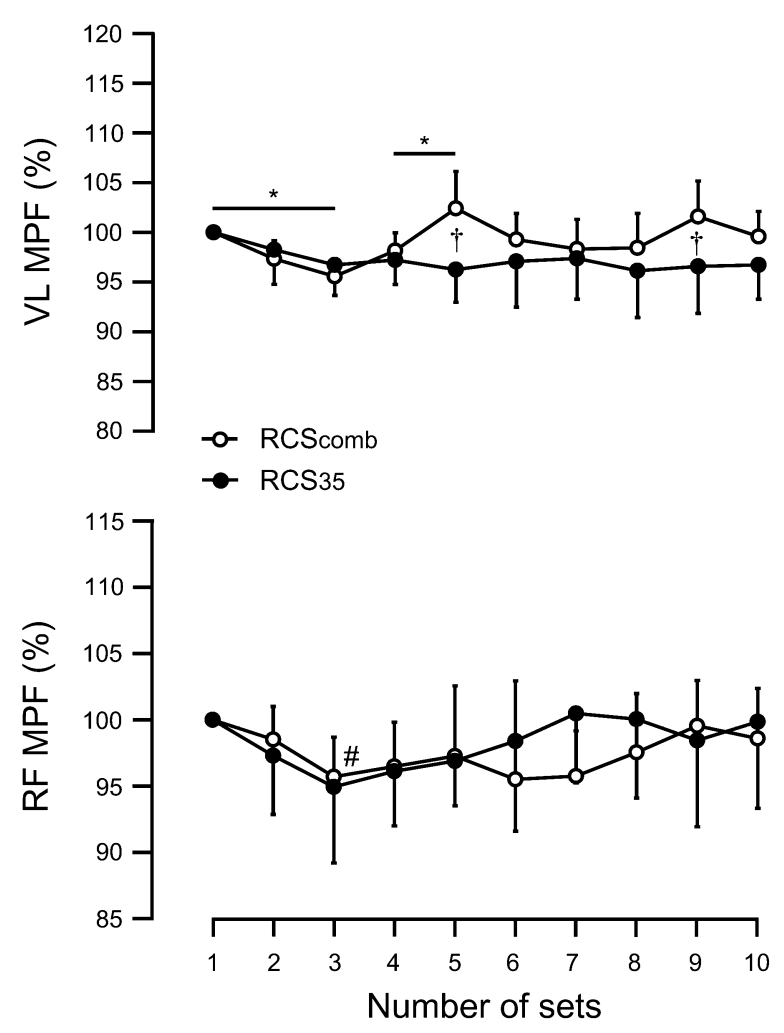

Fig. 5 Changes in mean power frequency (MPF) from the left vastus lateralis (VL: top) and from the left rectus femoris (RF: bottom) normalized by the 1 st set value during $\operatorname{RCS}_{\text {comb }}(\bigcirc)$ and $\operatorname{RCS}_{35}(\bullet)$. *: significantly different $(p<0.05)$ in $\mathrm{RCS}_{\text {comb }}$ \#: significantly different $(p<0.05)$ from the value in the 1 st set. $\dagger$ : significant difference $(p<0.05)$ between the value in $\operatorname{RCS}_{\text {comb }}$ and $\operatorname{RCS}_{35}$.

were significantly higher than those in the same sets during $\mathrm{RCS}_{35}$.

\section{Discussion}

The main finding in the present study was that PPO in the 5 th set of $\mathrm{RCS}_{\text {comb }}$ recovered to that in the 1st set, but that PPO in the 9th set of $\mathrm{RCS}_{\mathrm{comb}}$ did not recover to that in the 1st set.

In the present study, we expected that a 350-s recovery period would allow $\mathrm{PCr}$ to be completely resynthesized. Although PCr content was not directly measured in the present study, the PCr store immediately before each cycling sprint can roughly be estimated from the $\mathrm{preV}_{2}$ recorded in the present study (Matsuura et al., 2006) since Rossiter et al. (2002) reported that restoration of $\mathrm{PCr}$ after high-intensity exercise corresponds to decrease in $\dot{\mathrm{V}}_{2}$ during the recovery period. Since there was no significant difference between $\operatorname{preV}_{2}$ in the 5th set and that in the 9th set in $\mathrm{RCS}_{\text {comb }}$, it is inferred that in $\mathrm{RCS}_{\text {comb }}$ the PCr store immediately before the 5th set was very similar to that immediately before the 9 th set. In $\mathrm{RCS}_{\text {comb }}$, pre $\mathrm{VO}_{2}$ values in the 5 th and the 9th sets were significantly higher than the value in the 1 st set. This higher $\mathrm{preVO}_{2}$ in the 5th and 9th sets may be explained by the fact that active recovery was performed during recovery periods in RCS and was not performed before the 1st set. Recently, some researchers have suggested that accumulation of inorganic phosphate (Pi) due to $\mathrm{PCr}$ breakdown induces muscle fatigue (Westerblad et al., 2002). Since there is an almost stoichiometric increase in Pi with PCr breakdown (Sahlin et al. 1998), it is assumed that the magnitude of accumulation of Pi immediately before the 5 th set was very similar to that immediately before the 9 th set. Therefore, it is inferred that the difference between PPO in the 5th set and that in the 9th set in $\mathrm{RCS}_{\text {comb }}$ was not associated with $\mathrm{PCr}$ store and/or accumulation of $\mathrm{Pi}$.

In $\mathrm{RCS}_{\mathrm{comb}}$, blood La concentrations in the 5th and the 10th sets were $11.0 \pm 0.9$ and $14.0 \pm 3.1 \mathrm{mmol} \cdot \mathrm{L}^{-1}$, respectively. The difference between PPO in the 5th set and that in the 9th set may be associated with this difference in blood $\mathrm{La}$ concentrations. Reduction in muscle $\mathrm{pH}$ induced by lactic acid accumulation results in reductions in $\mathrm{Ca}^{2+}$ sensitivity (Fabiato and Fabiato, 1978; Godt and Nosek, 1989), maximal tension (Cooke et al., 1988; Godt and Nosek, 1989), and shortening velocity (Cooke et al., 1988). However, it has recently been shown in studies using mammalian muscle that these direct effects of reduced muscle $\mathrm{pH}$ on muscle contractility were absent at physiological temperatures (Pate et al. 1995; Westerblad et al. 1997). Consequently, it is likely that reduced muscle $\mathrm{pH}$ indirectly affects muscle contractility via the inhibition of ATP supply derived from anaerobic glycolysis (Sahlin et al., 1998). Therefore, there are the following three possible interpretations for the results of the present study. Firstly, there is a possibility that the reduced PPO in the 9th set during $\mathrm{RCS}_{\text {comb }}$ reflects this indirect effect of reduced muscle $\mathrm{pH}$. This idea is not in accord with the results of a study by Sahlin and Ren (1989) in which MVC was duplicated despite reduced muscle $\mathrm{pH}$. This discrepancy may be due to the difference between the exercise modality used in the present study and that used in the study by Sahlin and Ren (1989). The duration of MVC used in the study by Sahlin and Ren (1989) was $<2 \mathrm{~s}$, but it has been reported that power output during the 10 -s cycling sprint used in the present study reached a peak at $6.2 \mathrm{~s}$ on average (Matsuura et al., 2005). Indeed, Bogdanis et al. (1998) have shown that approximately $40 \%$ of the ATP utilized during a 6-10-s cycling sprint is supplied by anaerobic glycolysis. Thus, the energy supply process utilized during a 10 -s cycling sprint may be different from that during MVC of $<2$ s. PPO during a 10-s cycling sprint would be determined by not only PCr but also glycolysis.

Secondly, the reduced PPO in the 9th set during $\mathrm{RCS}_{\text {comb }}$ might reflect the alteration of the efferent motor command sent to exercising muscles by the central nervous system (CNS). Recent studies have suggested that the efferent motor command from the CNS to exercising muscle is modified by afferent information about peripheral metabolites to prevent premature fatigue and maintain homeostasis (Lambert et al., 2005; Noakes et al., 2005; St Clair Gibson et al., 2001). In the present study, the values of MPF from the VL in both the 5th and 9th sets were significantly higher in $\mathrm{RCS}_{\mathrm{comb}}$ than in 
$\mathrm{RCS}_{35}$. This result is consistent with that obtained by Matsuura et al. (2006). Matsuura et al. (2006) showed that MPF was lower during RCS with 35-s recovery periods than during RCS with 350-s recovery periods, suggesting that a severer metabolic state induces preferred recruitment of slow twitch motor units. In $\mathrm{RCS}_{\mathrm{comb}}$, MPF from the VL in the 5th set was significantly higher than that in the 4th set, but MPF from the VL in the 9th set was not significantly higher than that in the 8 th set. Therefore, the reduced PPO in the 9th set during $\mathrm{RCS}_{\text {comb }}$ might be induced by the efferent motor command altered subconsciously due to the lower muscle $\mathrm{pH}$.

Thirdly, according to Matsuura et al. (2006), there is also a possibility that interaction of the aforementioned two potential effects induced the reduction in PPO in the 9th set in $\mathrm{RCS}_{\text {comb }}$. In the 5 th set during $\mathrm{RCS}_{\mathrm{comb}}$, the negative effect of a blood La concentration of $10 \mathrm{mmol} \cdot \mathrm{L}^{-1}$ on PPO may be offset by the positive effect of increase in MPF on PPO. If the increase in MPF in the 9th set during $\mathrm{RCS}_{\text {comb }}$ were greater, the negative effect of blood La concentration of $14 \mathrm{mmol} \cdot \mathrm{L}^{-1}$ on PPO could be offset by the positive effect of the greater increase in MPF on PPO. However, in fact, the CNS might not increase the efferent motor command sent to the exercising muscles to maintain homeostasis (Lambert et al. 2005).

In the present study, trained subjects were used along with previous studies (Balsom et al. 1992; Ratel et al. 2002). Therefore, further research is required to determine whether interpretations of the present study can be applied to nontrained subjects.

In conclusion, a 350-s recovery period does not allow recovery of peak power output to its initial value under the condition of a blood La concentration of $14 \mathrm{mmol} \cdot \mathrm{L}^{-1}$ during repeated cycling sprints.

\section{References}

Arsac LM, Thiaudière E, Diolez P, Gerville-Réache L (2004) Parameter estimation in modeling phosphocreatine recovery in human skeletal muscle. Eur J Appl Physiol 91: 419-424

Ayalon A, Inbar O, Bar-Or O (1974) Relationships among measurements of explosive strength and anaerobic power. In: Nelson RC, Morehouse CA eds. Biomechanics IV. University Park Press, Baltimore: 527-532

Balsom PD, Seger JY, Sjödin B, Ekblom B (1992) Maximalintensity intermittent exercise: effect of recovery duration. Int J Sports Med 13: 528-533

Bogdanis GC, Nevill ME, Lakomy HKA, Boobis LH (1998) Power output and muscle metabolism during and following recovery from 10 and $20 \mathrm{~s}$ of maximal sprint exercise in humans. Acta Physiol Scand 163: 261-272

Cooke R, Franks K, Luciani GB, Pate E (1988) The inhibition of rabbit skeletal muscle contraction by hydrogen ions and phosphate. J Physiol 395: 77-97

Dawson B, Goodman C, Lawrence S, Preen D, Polglaze T, Fitzsimons M, Fournier P (1997) Muscle phosphocreatine repletion following single and repeated sprint efforts. Scand
J Med Sci Sports 7: 206-213

Fabiato A, Fabiato F (1978) Effects of pH on the myofilaments and the sarcoplasmic reticulum of skinned cells from cardiac and skeletal muscles. J Physiol 276: 233-255

Fitts RH (1994) Cellular mechanisms of muscle fatigue. Physiol Rev 74: 49-94

Gaitanos GC, Williams C, Boobis LH, Brooks S (1993) Human muscle metabolism during intermittent maximal exercise. J Appl Physiol 75: 712-219

Godt R, Nosek TM (1989) Changes of intracellular milieu with fatigue or hypoxia depress contraction of skinned rabbit skeletal and cardiac muscle. J Physiol 412: 155-180

Harris RC, Edwards RH, Hultman E, Nordesjo LO, Nylind B, Sahlin K (1976) The time course of phosphocreatine resynthesis during recovery of the quadriceps muscle in man. Pflugers Arch 367: 137-142

Hirvonen J, Rehunen S, Rusko H, Härkönen M (1987) Breakdown of high-energy phosphate compounds and lactate accumulation during short supramaximal exercise. Eur J Appl Physiol 56: 253-259

Hunter AM, St Clair Gibson A, Lambert MI, Nobbs L, Noakes TD (2003) Effects of supramaximal exercise on the electromyographic signal. Br J Sports Med 37: 296-299

Kay D, Marino FE, Cannon J, St Clair Gibson A, Lambert MI, Noakes TD (2001) Evidence for neuromuscular fatigue during high-intensity cycling in warm, humid conditions. Eur J Appl Physiol 84: 115-121

Lambert EV, St Clair Gibson A, Noakes TD (2005) Complex systems model of fatigue: integrative homoeostatic control of peripheral physiological systems during exercise in humans. Br J Sports Med 39: 52-62

Matsuura R, Ogata H, Horiuchi M, Yano T (2005) Physiological and psychological responses during repetition exercise. Jpn J Physiol Anthropol 10: 123-128 [In Japanese]

Matsuura R, Ogata H, Yunoki T, Arimitsu T, Yano T (2006) Effect of blood lactate concentration and the level of oxygen uptake immediately before a cycling sprint on neuromuscular activation during repeated cycling sprints. J Physiol Anthropol 25: 267-273

McCann DJ, Molé PA, Caton JR (1995) Phosphocreatine kinetics in humans during exercise and recovery. Med Sci Sports Exerc 27: 378-387

Moritani T, Nagata A, Muro M (1982) Electromyographic manifestation of muscular fatigue. Med Sci Sports Exerc 14: 198-202

Nevill ME, Bogdanis GC, Boobis LH, Lakomy HKA, Williams C (1996) Muscle metabolism and performance during sprinting. In: Maughan RJ, Shireffs SM eds. Biochemistry of Exercise IX. Human Kinetics, Champaign, 243-260

Noakes TD, St Clair Gibson A, Lambert EV (2005) From catastrophe to complexity: a novel model of integrative central neural regulation of effort and fatigue during exercise in humans: summary and conclusions. Br J Sports Med 39: 120-124 
Pate E, Bhimani M, Franks-Skiba K, Cooke R (1995) Reduced effect of $\mathrm{pH}$ on skinned rabbit psoas muscle mechanics at high temperatures: implications for fatigue. J Physiol 486: 689-694

Ratel S, Bedu M, Hennegrave A, Doré E, Duché P (2002) Effects of age and recovery duration on peak power output during repeated cycling sprints. Int J Sports Med 23: 397-402

Rossiter HB, Ward SA, Kowalchuk JM, Howe FA, Griffith JR, Whipp BJ (2002) Dynamic asymmetry of phosphocreatine concentration and $\mathrm{O}_{2}$ uptake between the on- and offtransients of moderate- and high-intensity exercise in humans. J Physiol 541: 991-1002

Sahlin K, Ren JM (1989) Relationship of contraction capacity to metabolic changes during recovery from a fatiguing contraction. J Appl Physiol 67: 648-654

Sahlin K, Tonkonogi M, Söderlund K (1998) Energy supply and muscle fatigue in humans. Acta Physiol Scand 162: 261-266

St Clair Gibson A, Schabort EJ, Noakes TD (2001) Reduced neuromuscular activity and force generation during prolonged cycling. Am J Regulatory Integrative Comp Physiol 281: R187-R196

Westerblad H, Bruton JD, Lännergren J (1997) The effect of intracellular $\mathrm{pH}$ on contractile function of intact, single fibres of mouse declines with increasing temperature. J Physiol 500: 193-204

Westerblad H, Allen DG, Lännergren J (2002) Muscle fatigue: lactic acid or inorganic phosphate the major cause? News Physiol Sci 17: 17-21

Received: August 17, 2006

Accepted: January 9, 2007

Correspondence to: Ryouta Matsuura, Laboratory of Exercise Physiology, Graduate School of Education, Hokkaido University, Kita-11, Nishi-7, Kita-ku, Sapporo 060-0811, Japan

Phone: +81-11-706-3422

Fax: +81-11-706-4943

e-mail: dj-ryota@edu.hokudai.ac.jp 